\title{
ИССЛЕДОВАНИЕ СТРУКТУРЫ НЕЙТРАЛЬНЫХ КИСЛОРОДСОДЕРЖАЩИХ СОЕДИНЕНИЙ ПЕРВИЧНЫХ СМОЛ БУРОГО УГЛЯ КАНСКО-АЧИНСКОГО БАССЕЙНА. 1
}

\author{
(Представил Н. Клесмент)
}

Цель работы - исследование структуры нейтральных кислородсодержащих соединений (НКС), выделенных из смол термодеструкции бурого угля Березовского месторождения Канско-Ачинского бассейна в условиях, исключающих высокотемпературный пиролиз парогазовых продуктов.

Первичная смола получена на установке ['] и подвергнута групповому анализу [ $\left.{ }^{2}\right]$. Выход НКС $-15,5 \%$ (мас. от безводной смолы).

Характеристика молекулярной структуры исходных НКС составлена на основании обобщения данных ИК-, УФ- и 'Н-ЯМР-спектроскопии, хромато-масс-спектрометрии, подтвержденных результатами элементного и функционального анализов, величиной молекулярной массы.

Установлено, что первичные буроугольные НКС представляют собой сложную многокомпонентную смесь соединений различных классов, углеродный скелет которых построен из ароматических, в меньшей степени нафтеновых циклов, с большим вкладом длинных алифатических цепей, в том числе содержащих непредельные связи. Из функциональных групп преобладают кетонные (алифатические и алкилароматические), сложноэфирные, лактонные, хиноидные, алкоксильные и гидроксильные группы, кислород и азот в составе гетероциклов.

Принимая во внимание сложность состава и полифункциональный характер НКС, было принято решение разделить их сначала методом колоночной жидкостной хроматографии на более однородные как по размеру молекул, так и по функциональному составу и типу углеродного скелета элюаты, а затем к последним применить тонкослойную хроматографию (ТСХ). Оба метода являются мягкими, не вызывающими искажений в структуре исходных соединений.

Исходные НКС подвергали вакуумной ректификации с отделением фракции с $T_{\text {кип }}$ ниже $150^{\circ} \mathrm{C}$, которую анализировали методом капиллярной газожидкостной хроматографии на приборе «Hewlett-Packard $5840 \mathrm{~A}$. Колонка капиллярная, кварцевая (длиной 50 м и диаметром 0,25 мм) с OV-101, газ-носитель - аргон.

Применение стандартных соединений и индексов Ковача позволило идентифицировать:

1. Кетоны $(75,13 \%$ мас.): ацетон, метилэтилкетон, диэтилкетон, пентанон-2, гексанон-2, изогексанон-2, октанон- 2 , изооктанон-2, нонанон-2, изононанон- 2 , деканон-2, изодеканон-2, додеканон-2, изододеканон-2, циклопентанон, 2-метилциклопентанон, циклогексанон, флуоренон, ацетофенон, 2-метилацетофенон, 3-метилацетофенон, 4-метилацетофенон, 2,3-, 2,4-, 2,5-диметилацетофенон, пропиофенон, 2-метилпропиофенон, 
4-метилпропиофенон, 2,3-, 2,4-, 3,4- и 3,5-диметилпропиофенон, бутирофенон, бензофенон.

2. Спирты $(12,22 \%$ мас.): циклогексанол, 4-метилциклогексанол, гептанол-1, октанол-1, изооктанол-1, нонанол-1, изононанол-1, деканол-1, ундеканол-1, додеканол-1, тридеканол-1, бензиловый спирт.

3. Эфиры $(0,74 \%$ мас.): анизол, фенетол, бензилацетат, 2- и 4-толилацетат, дифенилоксид.

4. Лактоны $(0,45 \%$ мас.): бутиролактон, валеролактон.

5. Производные бензофурана (3,76\% мас.): бензофуран, 1-метилбензофуран, 3-метилбензофуран, дибензофуран, 1-метилдибензофуран, 2-метилдибензофуран, 3-метилдибензофуран, 1,2- и 2,3-бензодифениленоксид.

6. Углеводороды $(0,65 \%$ мас.): азулен, инден, дурол.

7. Неидентифицированные $(7,05 \%$ мас.).

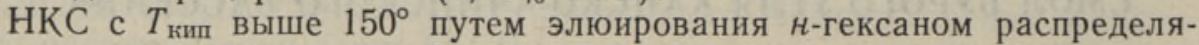
лись на четырехсекционной хроматографической колонке со следующей последовательностью сорбентов: целлюлоза, силикагель DF-5, оксид алюминия(III) нейтральный, целит-545. Элюирование колонки гексаном продолжали до тех пор, пока коэффициент преломления элюата не становился равным коэффициенту преломления растворителя. Затем колонку разъединяли на секции, и НКС, удерживаемые каждым из сорбентов, элюировали растворителями в соответствии со схемой анализа (рис. 1). Получили 15 элюатов, характеристику которых составляли по результатам ИК-, УФ- и ${ }^{1} \mathrm{H}$-ЯМР-спектроскопии, элементного и функционального анализов, криоскопии.

При этом выявлено следующее:

1. Соединения элюата 1 представлены поликонденсированной ароматикой очень высокой степени непредельности. Установлено присутствие терпенов. Из кислородсодержащих функциональных групп, присущих данному элюату, доминирующими являются кетонные и фенольные. Азот, в основном, в составе гетероциклов.

2. Элюат 2.1 представлен длинноцепочечной ароматикой (возможно, и изопреноидами и терпенами). Из кислородных групп обнаружены кетонные и хиноидные. В элюате 2.2 присутствуют сложноэфирные и лактонные группы. Азот в составе элюатов 2.1 и 2.2 практически отсутствует.

3. Элюат 3 по типу углеродного скелета построен из ароматических колец, алкильные заместители, как правило, короткие. Заметную долю элюата составляют терпеновые структуры. Высоким является содержание циклических кетонов. Идентифицирован гетероциклический азот.

4. Соединения элюата 4 весьма близки по типу углеродного скелета к элюату 3. Различия отмечены только в количественном содержании функциональных групп.

5. Элюат 5 содержит в себе высококонденсированные, высокоароматизированные структуры исключительно высокой степени непредельности. Наибольшую интенсивность имеют полосы поглощения фенольных гидроксилов, сложных эфиров и лактонных циклов. Весьма существенен вклад азота, преимущественно в гетероциклической форме с преобладанием пиррольных циклов, возможно присутствие амидных и. других форм.

6. Для соединений элюата 6 характерно высокое содержание терпеновых и иных непредельных структур. Выделяются полосы поглощения гидроароматических компонентов и хиноидных групп, а также гетероциклического кислорода и лактонных циклов. 
7. Элюат 7 представлен, в основном, ароматическими циклами с заместителями, имеющими кратные связи. Особенностью элюата является высокая концентрация гетероциклического кислорода.

8. Соединения элюата 8 близки по составу к элюату 7 , но имеют пониженную степень непредельности, повышенные ароматичность и степень конденсации, концентрация кетонных и фенольных групп значительно выше, чем в элюате 7. Из форм азота отмечается гетероциклическая и, возможно, лактамная.

9. Элюаты 9 и 10 весьма близки по составу. Это высокоароматизированные структуры исключительно высокой степени непредельности. Наибольшую интенсивность имеют полосы поглощения фенольных гидроксилов, сложноэфирных групп и лактонных циклов. Азот преимущественно в гетероциклах с преобладанием пирролов, возможно присутствие амидов.

10. Элюат 11.1 резко отличается от других отсутствием ароматики и наличием длинноцепочечных алифатических кетонов, преимущественно нормального строения, кетонов жирного ряда с олефиновыми связями и сложноэфирными группами.

11. У элюата 11.2 высокое содержание ароматики и намного выше степень непредельности, чем у элюата 11.1. Характерным для данного элюата является присутствие дикетонов, значительна роль лактонов. Азот в элюатах 11.1 и 11.2 отсутствует.

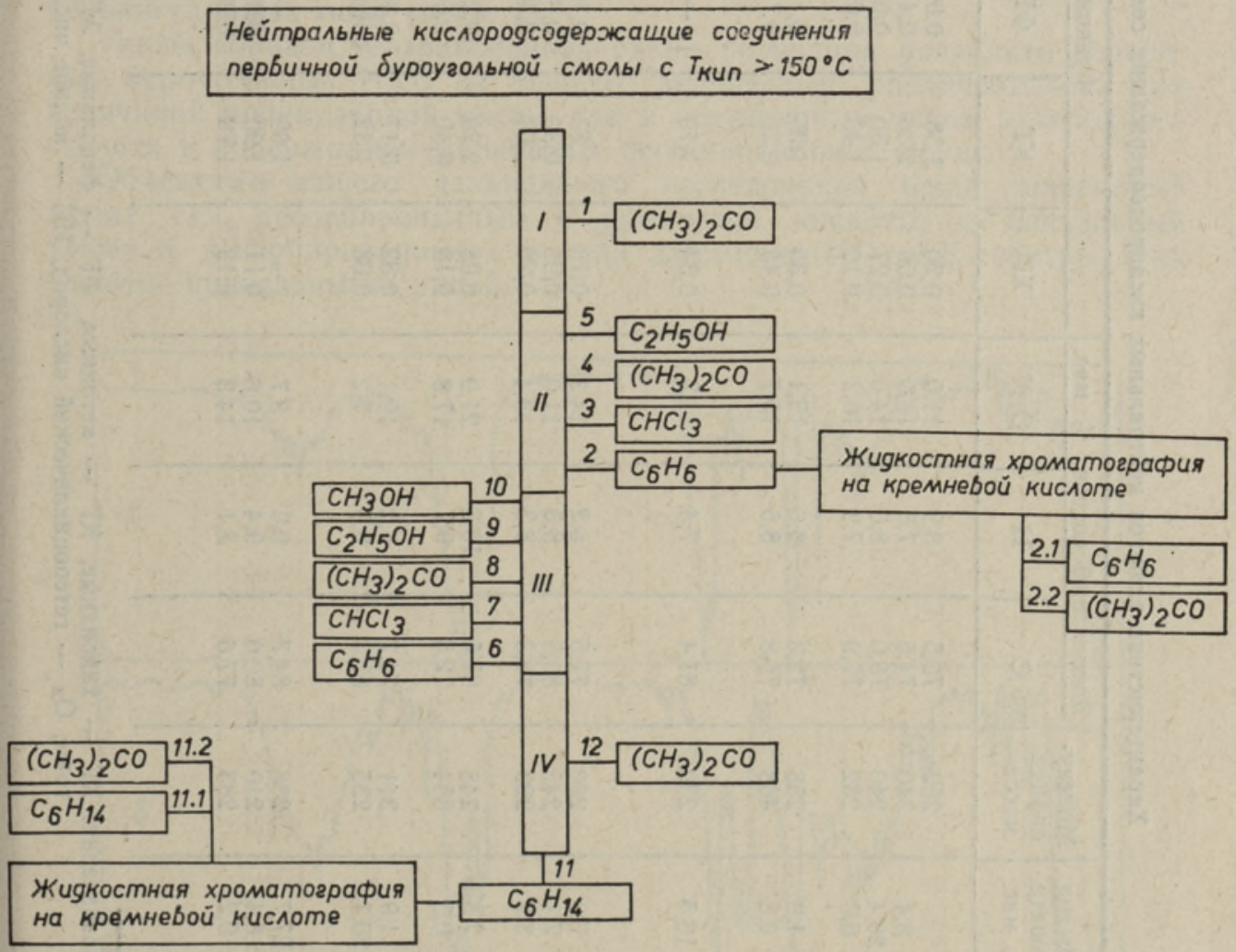

Рис. 1. Схема разделения нейтральных кислородсодержащих соединений первичной каменноугольной смолы.

I - целлюлоза, II - силикагель DF-5, III - оксид алюминия (III) нейтральный, IV - целит-545. 


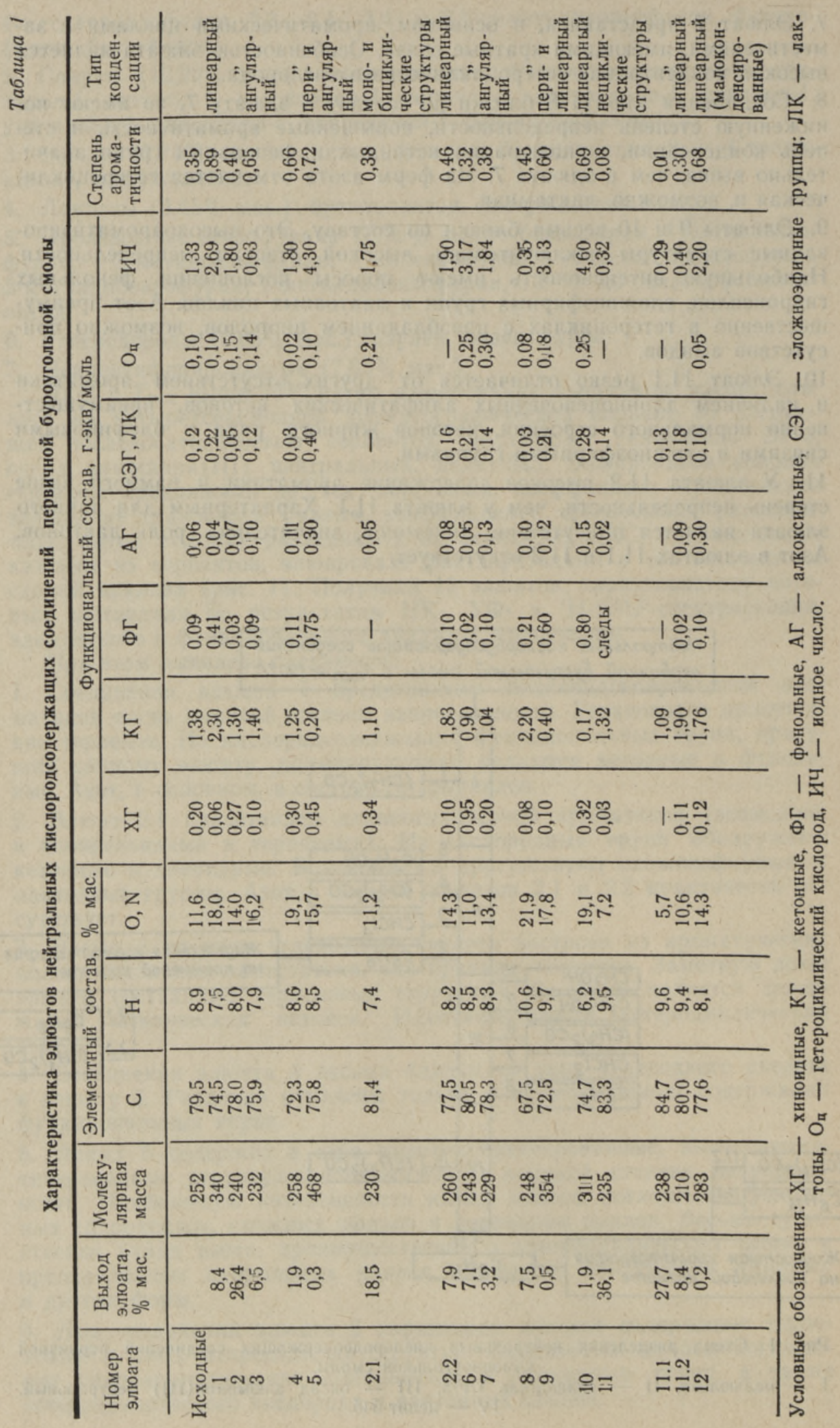


12. Соединения элюата 12 характеризуются высокой степенью непредельности. Ароматике, входящей в его состав, свойственна высокая замещенность. Повышенной интенсивностью отличаются полосы поглощения алкоксильных групп.

Молекулярная масса элюатов изменяется от 210 до 468. Основу функциональных групп составляют кетонные, содержащиеся в количестве более одной карбонильной группы на среднестатистическую молекулу (табл. 1).

Фенольные группы концентрируются в этанольных и метанольных элюатах (рис. 1, табл. 1), где их содержание находится в пределах $0,60-0,80$ г-экв/моль; в большинстве же элюатов не превышает 0,41 г-экв/моль.

В равной степени малохарактерными для буроугольных НКС являются гетероциклический кислород, алкоксильные и сложноэфирные группы, лактоны. Хиноидные группы для большинства элюатов определены лишь в количестве от 0,03 до 0,45 г-экв/моль, повышенной их концентрацией выделяется только элюат $6-0,95$ г-экв/моль. Величина иодного числа изменяется от 0,29 до 4,60 г-экв/моль, что намного выше аналогичного показателя для каменноугольных НKC [ $\left.{ }^{3}\right]$.

Исходя из относительной интенсивности полос поглощения ароматики и гидрированных колец была определена средняя степень ароматичности элюатов: наименее ароматичным является элюат $11.1(0,01)$, наиболее - элюат $1(0,89)$.

ИК- и УФ-спектроскопия показали доминирование линеарного типа конденсации колец в элюатах НКС, хотя имеются и ангулярный, и периангулярный типы (табл. 1).

Таким образом, разработанная схема позволила разделить первичные буроугольные НКС на элюаты, значительно различающиеся как величиной молекулярной массы, так и структурным типом углеродного скелета и содержанием различных функциональных групп.

Объектами нашего дальнейшего исследования были гексановый элюат 11.1, десорбированный с кремневой кислоты, и бензольный элюат 6 , десорбированный с оксида алюминия(III). ИК-спектры этих элюатов приведены на рис. 2.

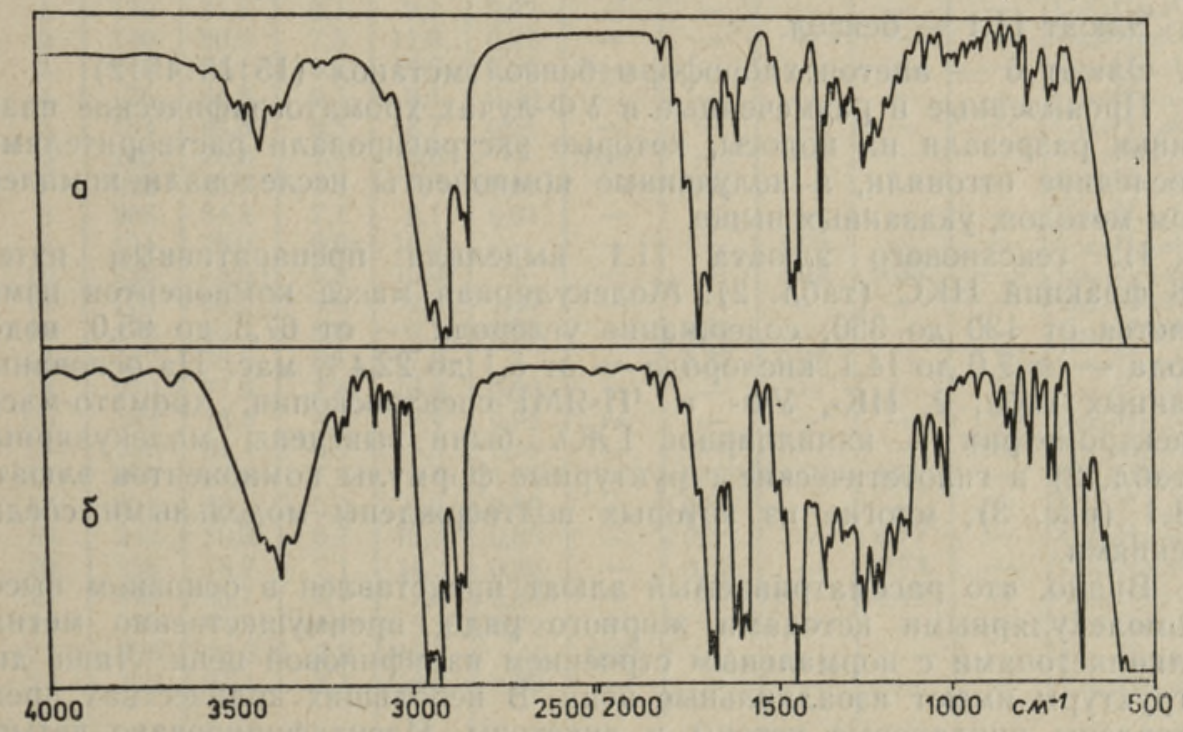

Рис. 2. ИК-спектры элюатов нейтральных кислородсодержащих соединений: $a$ гексановый 11.1, б - бензольный 6. 
Характеристика соединений элюата $\mathbf{1 1 . 1}$

\begin{tabular}{|c|c|c|c|c|c|c|c|c|}
\hline \multirow{2}{*}{ 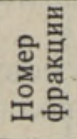 } & \multirow{2}{*}{ 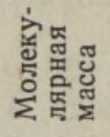 } & \multicolumn{3}{|c|}{$\begin{array}{l}\text { Элементный состав, } \\
\text { \% мас. }\end{array}$} & \multicolumn{3}{|c|}{$\begin{array}{c}\text { Функциональный } \\
\text { состав, г-экв/моль }\end{array}$} & \multirow{2}{*}{$\begin{array}{c}\text { Молекулярная } \\
\text { формула }\end{array}$} \\
\hline & & $\mathrm{C}$ & $\mathrm{H}$ & $\mathrm{O}$ & KГ & СЭГ & ИЧ & \\
\hline 1 & 150 & 78,9 & 10,5 & 10,6 & 0,30 & - & - & $\mathrm{C}_{9,9} \mathrm{H}_{15,8} \mathrm{O}_{1,0}$ \\
\hline 2 & 161 & 79,5 & 10,8 & 9,7 & 0,78 & - & - & $\mathrm{C}_{10,7} \mathrm{H}_{17,4} \mathrm{O}_{1,0}$ \\
\hline 3 & 166 & 79,2 & 10,7 & 10,1 & 0,74 & - & - & $\mathrm{C}_{11,0} \mathrm{H}_{17,8} \mathrm{O}_{1,1}$ \\
\hline 4 & 130 & 81,8 & 7,6 & 10,6 & 0,92 & - & - & $\mathrm{C}_{8,9} \mathrm{H}_{9,9} \mathrm{O}_{0,9}$ \\
\hline 5 & 154 & 76,9 & 12,8 & 10,3 & 0,90 & - & - & $\mathrm{C}_{9,9} \mathrm{H}_{19,7} \mathrm{O}_{1,0}$ \\
\hline 6 & 159 & 77,9 & 11,7 & 10,4 & 0,88 & - & 0,911 & $\mathrm{C}_{10,3} \mathrm{H}_{18,6} \mathrm{O}_{1,0}$ \\
\hline 7 & 173 & 77,6 & 12,9 & 9,5 & 0,87 & - & - & $\mathrm{C}_{10,2} \mathrm{H}_{22,3} \mathrm{O}_{1,0}$ \\
\hline 8 & 165 & 78,6 & 11,9 & 9,5 & 0,89 & - & 0,99 & $\mathrm{C}_{10,8} \mathrm{H}_{19,6} \mathrm{O}_{1,0}$ \\
\hline 9 & 190 & 78,3 & 13,0 & 8,7 & 0,90 & - & - & $\mathrm{C}_{12,4} \mathrm{H}_{24,7} \mathrm{O}_{1,0}$ \\
\hline 10 & 242 & 85,0 & 8,3 & 6,7 & 0,97 & - & - & $\mathrm{C}_{17,1} \mathrm{H}_{20,1} \mathrm{O}_{1,0}$ \\
\hline 11 & 231 & 68,5 & 10,1 & 21,4 & 0,71 & 0,92 & - & $\mathrm{C}_{12,6} \mathrm{H}_{23,3} \mathrm{O}_{3,1}$ \\
\hline 12 & 248 & 81,6 & 12,0 & 6,4 & 0,82 & - & 1,95 & $\mathrm{C}_{16,9} \mathrm{H}_{29,8} \mathrm{O}_{1,0}$ \\
\hline 13 & 250 & 80,3 & 13,4 & 6,3 & 0,82 & - & - & $\mathrm{C}_{16,7} \mathrm{H}_{33,5} \mathrm{O}_{1,0}$ \\
\hline 14 & 200 & 79,6 & 12,2 & 8,2 & 0,70 & - & - & $\mathrm{C}_{12,6} \mathrm{H}_{24,4} \mathrm{O}_{1,0}$ \\
\hline 15 & 267 & 80,6 & 13,4 & 6,0 & 0,84 & - & - & $\mathrm{C}_{17,9} \mathrm{H}_{35,8} \mathrm{O}_{1,0}$ \\
\hline 16 & 210 & 67,3 & 10,3 & 22,4 & 0,83 & 0,90 & - & $\mathrm{C}_{11,8} \mathrm{H}_{21,6} \mathrm{O}_{2,9}$ \\
\hline 17 & 206 & 82,3 & 9,8 & 7,9 & 0,91 & - & - & $\mathrm{C}_{14,1} \mathrm{H}_{20,1} \mathrm{O}_{1,0}$ \\
\hline 18 & 249 & 79,7 & 14,1 & 6,2 & 0,77 & - & - & $\mathrm{C}_{16,5} \mathrm{H}_{35,1} \mathrm{O}_{1,0}$ \\
\hline 19 & 232 & 68,5 & 10,5 & 21,0 & 0,79 & 0,89 & - & $\mathrm{C}_{12,7} \mathrm{H}_{23,4} \mathrm{O}_{3,0}$ \\
\hline 20 & 230 & 68,0 & 10,3 & 21,7 & 0,75 & 0,85 & - & $\mathrm{C}_{12,5} \mathrm{H}_{23,7} \mathrm{O}_{3,1}$ \\
\hline 21 & 238 & 80,0 & 13,3 & 6,7 & 0,90 & - & - & $\mathrm{C}_{15,9} \mathrm{H}_{31,7} \mathrm{O}_{1,0}$ \\
\hline 22 & 250 & 80,3 & 13,4 & 6,3 & 0,93 & - & - & $\mathrm{C}_{16,7} \mathrm{H}_{33,5} \mathrm{O}_{1,0}$ \\
\hline 23 & 260 & 80,6 & 13,4 & 6,0 & 0,93 & - & - & $\mathrm{C}_{17,5} \mathrm{H}_{34,8} \mathrm{O}_{1,0}$ \\
\hline 24 & 272 & 80,9 & 13,5 & 5,6 & 0,91 & - & - & $\mathrm{C}_{18,3} \mathrm{H}_{36,7} \mathrm{O}_{1,0}$ \\
\hline 25 & 290 & 81,1 & 13,5 & 5,4 & 0,88 & - & - & $\mathrm{C}_{19,6} \mathrm{H}_{39,2} \mathrm{O}_{1,0}$ \\
\hline 26 & 302 & 81,3 & 13,6 & 5,1 & 0,79 & - & - & $\mathrm{C}_{20,5} \mathrm{H}_{41,1} \mathrm{O}_{1,0}$ \\
\hline 27 & 322 & 84,1 & 10,8 & 5,1 & 0,99 & - & 0,94 & $\mathrm{C}_{22,6} \mathrm{H}_{34,8} \mathrm{O}_{1,0}$ \\
\hline 28 & 350 & 78,2 & 12,7 & 9,1 & 1,74 & - & - & $\mathrm{C}_{22,8} \mathrm{H}_{44,5} \mathrm{O}_{2,0}$ \\
\hline
\end{tabular}

При меч ан ие: условные обозначения см. в табл. 1 .

Оптимальное препаративное ТСХ-разделение компонентов элюатов достигнуто на пластинках «Силуфол» (ЧССР) в следующих системах:

1. Элюат 11.1 - бензол.

2. Элюат 6 - ацетон:хлороформ:бензол:метанол $(15: 15: 45: 2)$.

Проявленные и размеченные в УФ-лучах хроматографические пластинки разрезали на полосы, которые экстрагировали растворителями, последние отгоняли, а полученные компоненты исследовали комплексом методов, указанных выше.

Из гексанового элюата 11.1 выделили препаративным путем 28 фракций НКС (табл. 2). Молекулярная масса компонентов изменяется от 130 до 350; содержание углерода - от 67,3 до 85,0; водорода - от 7,6 до 14,1 , кислорода - от 5,1 до $22,4 \%$ мас. На основании данных табл. 2, ИК-, УФ- и ${ }^{1} \mathrm{H}$-ЯМР-спектроскопии, хромато-массспектрометрии и капиллярной ГЖХ были выведены молекулярные (табл. 2) и гипотетические структурные формулы компонентов элюата 11.1 (рис. 3), многие из которых подтверждены модельными соединениями.

Видно, что рассматриваемый элюат представлен в основном высокомолекулярными кетонами жирного ряда, преимущественно метилалкилкетонами с нормальным строением парафиновой цепи. Лишь две структуры имеют изоалкильные цепи. В небольших количествах представлены циклановые кетоны и дикетоны. Идентифицировано четыре структуры кетонов жирноароматического ряда с бензольным и нафтеновыми кольцами. 


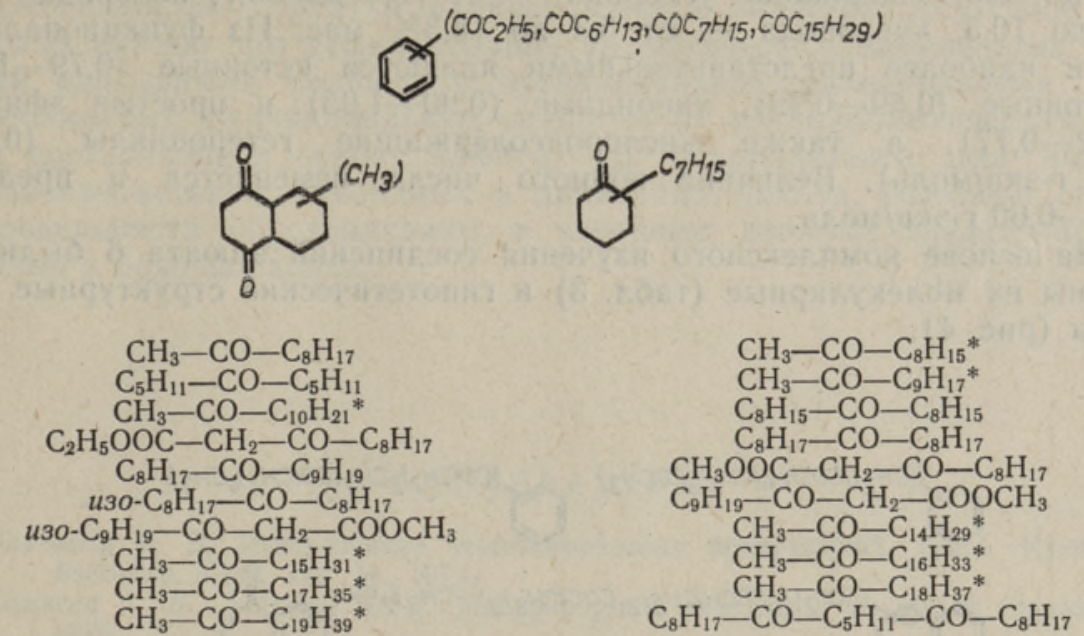

* Подтверждено на стандартах методом ГЖХ.

Рис. 3. Гипотетические структурные формулы первичных нейтральных кислородсодержащих соединений буроугольной смолы (гексановый элюат 11.1, десорбированный с кремневой кислоты).

Из бензольного элюата 6 выделили препаративным путем 24 фракции НКС (табл. 3). Молекулярная масса соединений изменяется от

Таблица 3

Характеристика соединений элюата 6

\begin{tabular}{|c|c|c|c|c|c|c|c|c|c|c|c|}
\hline \multirow{2}{*}{ 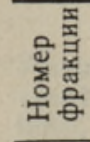 } & \multirow{2}{*}{ 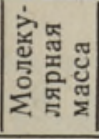 } & \multicolumn{3}{|c|}{$\begin{array}{c}\text { Элементный состав, } \\
\text { \% мас. }\end{array}$} & \multicolumn{3}{|c|}{ Функциональный } & \multicolumn{3}{|c|}{ состав, г-эКв/моль } & \multirow{2}{*}{$\begin{array}{l}\text { Молеку- } \\
\text { лярная } \\
\text { формула }\end{array}$} \\
\hline & & C & $\mathrm{H}$ & $\mathrm{O}$ & $\mathrm{K} \Gamma$ & ЛК & ИЧ & $\mathrm{X} \Gamma$ & ПрЭ* & $\mathrm{O}_{\text {म }}$ & \\
\hline 1 & 170 & & 9,1 & 9 & 92 & - & - & - & - & 一 & $C_{11}$, \\
\hline 2 & 14 & & 7 , & & & 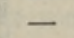 & $=$ & - & & - & \\
\hline 3 & 14 & & 8,1 & 1 & & - & - & - & & - & \\
\hline 4 & 17 & & 9,1 & 9 & & - & - & - & - & - & \\
\hline 5 & 18 & & 6 & 8 & 0,9 & 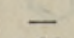 & - & - & - & - & \\
\hline 6 & & & 7,4 & 16,8 & & 0,99 & $\overline{-}$ & & & - & \\
\hline 7 & & & 7, & 7,2 & 0,88 & - & 0,50 & - & - & - & \\
\hline 8 & & 84 & 7,1 & 8,1 & 0,9 & - & - & & - & - & \\
\hline 9 & & & $6,($ & 16,0 & & - & - & 1,95 & - & - & \\
\hline 10 & & & 6 & & & - & 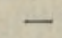 & 1,9 & 0,33 & - & \\
\hline 1 & & & 5, & 9 & 0,9 & - & - & - & - & & \\
\hline 1 & & & 8 , & & 0,9 & - & 0,51 & - & - & & \\
\hline 13 & & 76 & 6 & 17 & & - & 0,30 & 0,90 & - & 0,76 & \\
\hline 1 & & & 3 & & 0 & - & 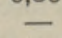 & 0,0 & & 1, & \\
\hline 15 & 28 & 78 & 4 & 17 & & - & - & - & 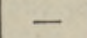 & 1, & \\
\hline 10 & & & 5 , & 13 & & - & & - & & 0,8 & \\
\hline it & & & 7 , & 8 & & - & 0,60 & - & 0,70 & - & \\
\hline 18 & & 83 & 10 , & & & - & & - & 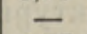 & - & \\
\hline 19 & & 80 & 6 , & 13 & 0 , & - & 0 & - & 0,77 & - & \\
\hline 20 & 2 & 78 & 7 , & 14 & 0,8 & 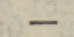 & 0,53 & - & 0,7 & - & \\
\hline 2 & 21 & 85 & 6,7 & 7, & 0, & 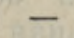 & & - & 0,12 & - & \\
\hline 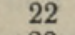 & 23 & 84 & 10,5 & 5 & 0,79 & & 11 & 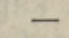 & - & 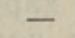 & \\
\hline 2 & 20 & 76 & 7,8 & 15,7 & - & 0,89 & - & - & - & - & \\
\hline 24 & 300 & 81,1 & 8,1 & 10,8 & 1,89 & & & & 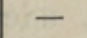 & & $0,0,31_{2}$ \\
\hline
\end{tabular}

* ПрЭ - простые эфиры (в том числе циклические), остальные обозначения см. в табл. 1 . 
140 до 300; содержание углерода - от 75,8 до 85,7 , водорода - от 3,8 до 10,5 , кислорода — от 5,3 до $18,3 \%$ мас. Из функциональных групп наиболее представительными являются кетонные $(0,79-1,89)$, лактонные $(0,89-0,99)$, хиноидные $(0,90-1,95)$ и простые эфирные $(0,12-0,77)$, а также кислородсодержащие гетероциклы $(0,76-$ 1,60 г-экв/моль). Величина иодного числа изменяется в пределах $0,30-0,60$ г-экв/моль.

На основе комплексного изучения соединений элюата 6 были выведены их молекулярные (табл. 3) и гипотетические структурные формулы (рис. 4).
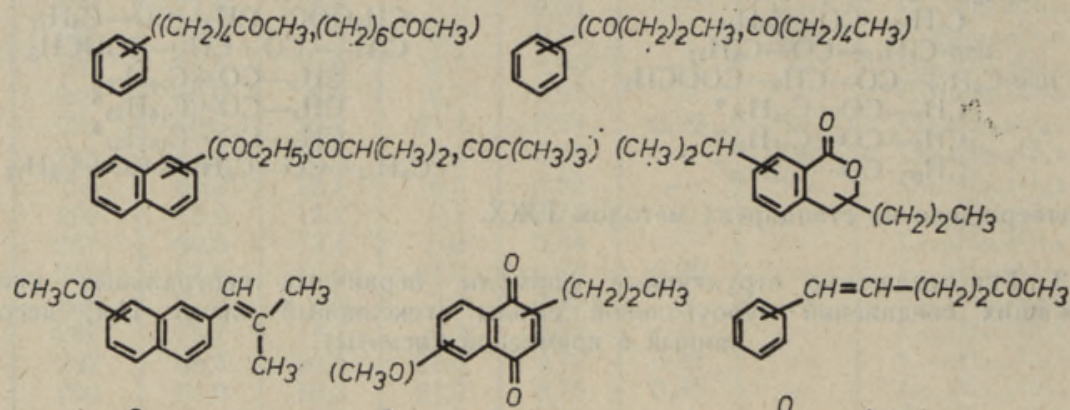<smiles></smiles><smiles>C=CCc1ccc2occc(=O)c2c1</smiles><smiles></smiles><smiles>O=C(Cc1ccccc1)c1ccc2occc2c1</smiles><smiles></smiles><smiles>C=C(C)c1ccccc1CC(C)=O</smiles><smiles></smiles><smiles>COc1cccc(CC(=O)c2ccccc2)c1</smiles>

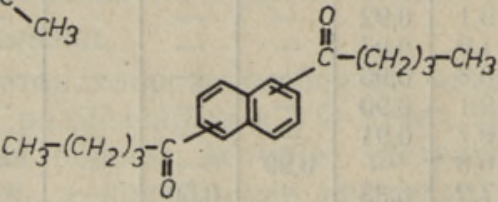

Рис. 4. Гипотетнческие структурные формулы первичных нейтральных кислородсодержащих соединений буроугольной смолы (бензольный элюат 6 , десорбированный с оксида алюминия(III)).

Основную долю элюата 6 составляют моно- и бициклические ароматические структуры с относительно длинными алкильными заместителями $\left(\mathrm{C}_{3}-\mathrm{C}_{7}\right)$ как нормального, так и изостроения. Около трети структур имеет двойные связи в боковой цепи. Для большинства соединений характерна карбонильная группа, либо сопряженная с ароматическим кольцом, либо расположенная в конце цепочки. Помимо кетонных групп, идентифицированы шестичленные лактонные циклы, хиноидные группы, $\gamma$-пироновый цикл. Подчиненная роль в данном элюате принадлежит пятичленным кислородным циклам и метоксильным группам. Одна из структур имеет шестичленный эфирный цикл. 
Особенностью структур данного элюата является отсутствие нафтеновых циклов при доминировании ароматических, замещенных длинными алкильными цепями, и превалирование разнообразных форм карбонильных функциональных групп - от алкилароматических кетонов, составляющих основу элюата, до диарилкетонов при наличии арилбензилкетонов, хиноидных и лактонных циклов. Высокую степень непредельности обусловливают в основном двойные связи, расположенные в боковых цепях.

\section{ЛИТЕРАТ УРА}

1. Платонов В. В. Исследование термохимических превращений углей Кузнецкого бассейна. Канд. дис. М., 1972.

2. Камнева А. И., Королев Ю. Г. Лабораторный практикум по химии топлива. М., 1975.

3. Платонов В., Клявина О., Нвлева Л. Исследование структуры нейтральных кислородсодержащих соединений первичной каменноугольной смолы. - Изв. АН ЭССР. Хим., 1984, 33, № 1, 15-20.

Тульский государственный педагогический институт
Поступила в редакцию $22 / \mathrm{XI} 1984$

V. PLATONOV, O. KLJAVINA, Niina TABOLENKO, L. IVLEVA

\section{KANSKI-ATŠINSKI BASSEINI \\ PRUUNSOE PRIMAARSEST UTTETORVAST SAADUD NEUTRAALSETE HAPNIKUUHENDITE STRUKTUURI UURIMINE. 1}

Pruunsöe primaarse uttetõrva neutraalseid hapnikuühendeid uuriti infrapunase, ultraviolett- ja tuuma magnetresonantsspektroskoopia, samuti elemendi- ja funktsionaalanalüüsi, krüoskoopia, kapillaargaasikromatograafia ja kromatomassispektromeetria abil. Mõned puhtad neutraalsed hapnikuühendid isoleeriti vedelikkolonn- ja preparatiivse ōhukese kihi kromatograafia abil. Saadud ühendeid uuriti keemiliste ja füüsikaliste meetoditega. On esitatud kahe eluaadi ühendite molekulaar- ja struktuurivalemid.

\section{PLATONOV, O. KLYAVINA, Nina TABOLENKO, L. IVLEVA}

\section{INVESTIGATION OF THE STRUCTURE OF NEUTRAL OXYGEN-CONTAINING COMPOUNDS FROM PRIMARY BROWN COAL TARS OF THE KANSK-ACHINSK BASIN. 1}

Neutral oxygen-containing compounds from primary brown coal tars were investigated by IR-, UV-, NMR-spectroscopy, routine and functional analysis, cryoscopy, capillary gas chromatography and chromato-mass-spectrometry. Some pure neutral oxygencontaining compounds were isolated by liquid column and preparative thin-layer chromatography.

The compounds obtained were investigated by chemical and physical methods. Molecular and structural formulas for the compounds of two eluates are proposed. 